\title{
The Case for Engineering as a Liberal Art
}

\section{Dr. R.F.A. Hamilton, Siena Heights University}

R.F.A. Hamilton is the Director of Engineering at Siena Heights University. His research interest primarily on improving student performance in entry level courses. His background is combination of Engineering, Physics, and Education. 


\section{The Case for Engineering as a Liberal Art}

Engineering is often viewed as a highly specialized and exclusive field of study. Typically, only those pursuing engineering degrees receive any training in engineering. In comparison, fields considered to be part of the liberal arts are studied at an introductory level by a great many students. Regardless of if they are pursuing degrees in those fields or not. The liberal arts are often considered integral to a comprehensive education. Over time the definition of a comprehensive education has expanded as knowledge has expanded. Technological advances of the past half century are reaching a point where engineering should be included in the liberal arts. An understanding of the basic principles of engineering is rapidly becoming integral to receiving a complete education. Most institutions have a required liberal arts or general education core. Engineering faculty need to push for the inclusion of engineering courses in this core. Adding engineering to the liberal arts benefits not only those outside of engineering but benefits engineers as well. The modern challenges facing engineers require not just a technical proficiency but also an understanding of the broader liberal arts. Solutions to these challenges will require greater and greater collaboration with those outside of engineering. Adding engineering to the roster of the liberal arts will help to bridge this gap.

It is important to understand how the liberal arts developed and how engineering developed as academic fields of study to determine how to best incorporate engineering into the liberal arts. The liberal arts are an idea as old as the academy itself. The beginnings of modern universities are typically traced back to the Athenian system of education employed in ancient Greece. The Athenian system was based on the trivium and the quadrivium. The trivium consisted of grammar, rhetoric, and logic. Study of the trivium proceeded study of the quadrivium. The quadrivium consisted of arithmetic, astronomy, geometry, and music theory ${ }^{6,1}$. The idea behind the quadrivium was that these were the essential skills a free person needed to function in civil society ${ }^{23}$. As the body of human knowledge grew the body of the liberal arts grew as well.

The Enlightenment brought the first major shift in the definition of the liberal arts and meaning of a liberal arts education. The liberal arts in the Enlightenment became a way for man to improve himself. Immanuel Kant advanced the idea of education to set man free ${ }^{15}$. Freedom in Kant's definition meant freedom from superstition and fear. The point of an education was to give one a better understanding of the world around them. Through this understanding came freedom. This moved the liberal arts from simply a body of knowledge to a set of skills derived from a body of knowledge. In the United States this became the basis of the modern liberal arts core seen in most universities today. The Morrill Act of 1862 and the second Morrill Act of 1890 which providing for the establishment of the public land grant institutions ${ }^{14}$, was the impetus for the idea of the liberal arts as the basis of a modern university education. The Morrill Acts included specific mention that the ideas of the liberal arts would be taught at the land grant institutions ${ }^{4}$.

Engineering education initially developed outside of the academy. It was primarily a vocational field in the beginning. Entering the profession of engineering was the result of 
apprenticeship style learning. Training took place on the job. As such, the profession was vocational $^{21}$. In the United States the Morell Act spurred universities to grow. This growth included the acquisition of engineering colleges, departments, and divisions ${ }^{18}$. These engineering programs, while a part of the university, were often separate and had little interaction with the larger university. Engineering students typically received very little instruction that was not directly tied to the learning and practice of engineering.

Over several decades, there has been a debate in engineering education over how much practical and how much theoretical knowledge engineering students receive. The result of this debate has resulted in undergraduate engineering programs that are heavy in engineering science. Such theoretically driven programs, have resulted in barriers that prevent those studying areas outside engineering from ever studying engineering. The typical model of engineering education in the U.S. consists of courses with long chains of prerequisites. The first class in the chain usually have a mathematical prerequisite. Barriers also exists for introductory courses which have no such prerequisite barriers. A growing trend is the introduction of freshmen level courses without mathematical prerequisites. However, these courses often impose restrictions limiting student enrollment to only those who have declared a major in engineering. The mathematical prerequisites and major restrictions, prevent those outside of engineering from gaining exposure to the basic ideas of engineering.

Typical engineering program models also limit engineering students' ability to study a wide array of areas in the traditional liberal arts. It is not uncommon for engineering disciplines in a university to require more than the standard 120 total semester hours for a bachelor's degree. Nor is it uncommon for engineering degrees to be among those requiring the most hours within the major field of study. Often students are left with only the minimum hours in general studies required by the university.

The founding of ABET, then known as the Engineers' Council for Professional Development, in $1932^{10}$ began to standardize and formalize engineering undergraduate programs in the United States and elsewhere. As time progressed it became evident that the amount of liberal arts education engineering students were receiving was not sufficient. The discipline of engineering was changing. To meet the demands of the changing industry ABET introduced the EC2000 standards ${ }^{10}$. The EC2000 standards included specific requirements for a broader education. These are often accomplished through specific courses in the broader university general education distributions requirements and engineering specific courses in economics, technical communications, and ethics. These engineering-centric courses further the divide between engineering and the liberal arts.

It is important to break the barrier between the study of the liberal arts and the study of engineering for the future of engineering. The issues faced by engineers in the near term and long term future are going to require collaboration with the broader liberal arts. This is readily seen in the 14 grand challenges of engineering unveiled by the National Academy of Engineering ${ }^{16}$. They represented a new direction in engineering. These grand challenges were:

- Advance Personalized Learning 
- Make Solar Energy Economical

- Enhance Virtual Reality

- Reverse-Engineer the Brain

- Advance Health Informatics

- Restore and Improve Urban Infrastructure

- Secure Cyberspace

- Provide Access to Clean Water

- Provide Energy from Fusion

- Prevent Nuclear Terror

- Manage the Nitrogen Cycle

- Develop Carbon Sequestration Methods

- Engineer the Tools for Scientific Discovery

These challenges cannot be solved by technical knowledge alone. To meet these challenges will require not only a technical knowledge and skills but also a more humanistic approach. It will also require more participation from practitioners of fields typically considered to be part of the liberal arts.

The grand challenges are those which will impact everyday life. Solutions to them will require interaction and collaboration between engineers and those from the broader liberal arts. Similarly, there is a need for those in other fields to have basic understanding of engineering. This need for a basic understanding is an outgrowth of the degree to which technology permeates and shapes modern society. Without an understanding of how and why technology is developed and implemented, it becomes an almost magical black box. A lack of understanding of how such technology functions and is developed is antithetical to the enlightenment idea of educating individuals so they understand the world around them. An understanding of the world is the basis on which the modern concepts of the liberal arts are based.

Engineering needs to be considered a liberal art. The purpose of a liberal arts education has always been to allow individuals to apply a broad set of skills and knowledge to solve problems effectively ${ }^{3}$. This is exactly what engineers do, applying broad knowledge and skills to solve problems. Traditionally, the liberal arts has referred to non-technical problems. However, the growing presence of technology in everyday life has made the separation of technical and non-technical skills an ill-defined boundary at best. The basics of engineering should be a required part of a liberal arts background.

The proposed basics are not specific technical skills. It is not possible for universities to keep up with the rapid change in technology. In the time frame needed to design a course and implement it, the technology will often have changed significantly ${ }^{20}$. Rather the basics include the basics of engineering design and practice. These are the materials covered in common freshmen introductory engineering courses. The natural sciences are included in the liberal arts. The inclusion of the natural sciences is based on the idea that students need to learn the scientific method, regardless of what discipline they learn it from, be it biology, physics, chemistry, etc... 
Similarly, students need to learn the basics of how to apply knowledge and how to use it to engineer an item to meet a need or want.

The purpose of studying the scientific method is to find explanations of the physical world. Engineering education will allow for building of explanations and understanding of the technological world. To refer to the enlightenment definition of the liberal arts above, one of the main components is that the liberal arts are to demystify the world. The study of the natural sciences does not demystify technological advance. Adding basic engineering courses will. The content of such a course is something that has been worked on for quite a while.

A majority of engineering programs now include some form of freshmen seminar or freshmen learning experience that assumes limited prior exposure to engineering. These courses are intended to introduce students to the basics of what it means to be an engineer and the essential functions of engineering. Such an experience is easily adapted into meeting the needs of a liberal arts course in basic engineering for non-engineering majors. Including basic engineering courses to a liberal arts education strengthens the pool of background knowledge that students can draw from later. Courses intended for non-majors also strengthen the engineering fields.

These introductory courses for engineering have been studied extensively and shown to have positive impacts upon retention of engineering student ${ }^{11,12,19,22}$. An introductory course for non-engineering majors could borrow from the design of courses such as these. Such courses would also borrow from best practices used in "conceptual physics" classes. Conceptual physics classes are ones designed for non-science majors. These courses are not calculus based or even particularly algebra based. Rather they introduce the phenomena of physics then support it with short, very basic equations. Often these classes are found on campuses under names such as "Physics for Poets" or "Physics of Toys".

Putting these two together would result in a project based course focused on the design cycle. Students could work to create several smaller projects following the design cycle. Introduction and small scale projects would allow students to develop familiarity with the design cycle. There exist a large number of well used engineering projects, such as the mouse-trap car, Rube Goldberg devices, toothpick bridges, cardboard canoes, and etc. These small projects can be supplemented with case studies and student research on real world design processes.

The course could be divided into modules, with each module focused on one project. For example, a module could be centered on building a toothpick bridge. At the beginning of the unit students could be given a set of design criteria for a bridge they must construct. The criteria can include weight and size constraints, material constraints, how much load it must handle, or any number of other requirements. As students plan their solution, different bridge designs can be introduced such as suspension bridges, truss bridges, or arch bridges. Case studies of the designs of famous bridges can be used. This can include bridges which work are lauded for innovation and those which failed. Throughout the unit students can build and test various designs for their own bridge. 
Courses intended for non-engineering majors also strengthens engineering as a discipline by allowing for more cooperation across disciplines. One challenge often faced in collaboration is a basic lack of understanding of what engineering is and how engineering functions. The basic "language" as it were, of engineering is foreign to those from other fields. In solving the grand challenges of engineering such cross collaboration is going to be vital. Someone educated in even the most basic principles of engineering will be able to collaborate in a more meaningful way.

The best way to foster this collaboration is for faculty to push universities to include engineering courses in their liberal arts core. Most universities have a general studies core required of all students. This core has different names at different institutions, liberal arts, general studies, essential studies, etc. Engineering faculty need to push for the inclusion of engineering among the liberal arts core.

The 14 grand challenges solutions will require collaboration with non-engineers. The solutions will not only need to be technologically innovative, but also account for how people will use them and interact with them. It is this phase of the solution that will require collaboration with those outside of engineering. The adoption of innovative technologies is affected by many variables outside of engineering ${ }^{2,13}$. The introduction of engineering courses as part of the broader liberal arts will help spur this collaboration. The cross training of those outside of engineering in the basics of engineering design will allow for future development of solutions that are not only technologically innovative, but will also be used by society.

The definition of the liberal arts has changed over time. As knowledge has advanced, the areas considered liberal arts has increased. Over time, the basic idea behind a liberal arts education has remained the same; to prepare someone to be able to comprehend and participate in society. The penetration of technology into everyday life justifies including engineering in the liberal arts. The inclusion benefits both engineers and non-engineers. Engineering faculty need to push for inclusion in the liberal arts core of their universities. Exposing those from other fields of study to engineering broadens their knowledge base. The grand challenges facing engineering are going to require collaboration with those from other fields to solve. Engineering as a liberal arts exposes others to the principles of engineering and well enable the types of collaborations needed to solve these problems.

\section{Bibliography}

[1] Abelson, Paul. The seven liberal arts: a study in mediaval culture. Vol. 11. Teachers' College, Columbia University, 1906.

[2]Adner, R., \& Kapoor, R. "Innovation ecosystems and the pace of substitution: Re-examining technology Scurves." Strategic Management Journal. (2015). 
[3] Association of American Colleges \& Universities (2015). What is a $21{ }^{\text {st }}$ Century Liberal Education. Retrieved from https://www.aacu.org/leap/what-is-a-liberal-education

[4] Boning, Kenneth. "Coherence in general education: A historical look." The Journal of General Education 56.1 (2007): 1-16.

[5] Bucciarelli, Louis L., and David E. Drew. "Liberal studies in engineering-a design plan." Engineering Studies (2015): 1-20.

[6] Duderstadt, James J. "Engineering for a Changing Road, A Roadmap to the Future of Engineering Practice, Research, and Education." (2007).

[7] Dym, Clive L., et al. "Engineering design thinking, teaching, and learning. "Journal of Engineering Education 94.1 (2005): 103-120.

[8] Froyd, Jeffrey E., Phillip C. Wankat, and Karl Smith. "Five major shifts in 100 years of engineering education." Proceedings of the IEEE 100.Special Centennial Issue (2012): 1344-1360.

[9] Hecker, Patricia A. "Successful consulting engineering: a lifetime of learning." Journal of Management in engineering 13.6 (1997): 62-65.

[10] History. (2015, October 14). Retrieved from http://www.abet.org/about-abet/history/

[11]Hoit, M., \& Ohland, M. "The Impact of a Discipline-Based Introduction to Engineering Course on Improving Retention." Journal of Engineering Education 87.1(1998): 79-85.

[12]Knight, D. W., Carlson, L. E., \& Sullivan, J. F. "Staying in engineering: Impact of a hands-on, team-based, firstyear projects course on student retention." age, 8 (2003): 1.

[13]König, A., Kammerlander, N., \& Enders, A. "The family innovator's dilemma: How family influence affects the adoption of discontinuous technologies by incumbent firms." Academy of Management Review, 38.3, (2013): 418441.

[14] Modern Liberal Arts, Trivium and Qaudrivium. (2015, October 14). Retrieved from http://mla.winchester.ac.uk/?page_id=92

[15] Munzel, G. Felicitas. "Kant on Moral Education, or" Enlightenment" and the Liberal Arts." The Review of Metaphysics (2003): 43-73.

[16] NAE Grand Challenges for Engineering. (2015, October 14). Retrieved from http://www.engineeringchallenges.org/challenges.aspx

[17] Nieusma, Dean. "Conducting the instrumentalists: a framework for engineering liberal education." Engineering Studies 7.2-3 (2015): 159-163.

[18] Reynolds, Terry S. "The education of engineers in America before the Morrill Act of 1862." History of Education Quarterly (1992): 459-482.

[19]Richardson, J., \& Dantzler, J. (2002, November). Effect of a freshman engineering program on retention and academic performance. In Frontiers in Education, 32nd Annual Vol. 3, (2002): pp. S2C-16.

[20] Rugarcia, Armando, et al. "The future of engineering education I. A vision for a new century." Chemical Engineering Education 34.1 (2000): 16-25.

[21] Seely, Bruce E. "Patterns in the history of engineering education reform: A brief essay." Educating the engineer of 2020: Adapting engineering education to the new century (2005): 114-130. 
[22]Willson, V. L., Monogue, T., \& Malave, C. (1995, November). First year comparative evaluation of the Texas A\&M freshman integrated engineering program. In Frontiers in Education Conference, Proceedings. Vol. 1, (1995): pp. 3a6-13).

[23] West, A. F. (1912). The Seven Liberal Arts. In Perrin, C. A. (Editor), Alcuin And the Rise of the Christian Schools. Charles Scribner's Sons. 